\title{
Ebstein's anomaly associated with splenomegaly and reversible hypersplenism
}

\author{
M R Bennett, M F Shiu
}

\begin{abstract}
A case of Ebstein's anomaly associated with chronic right heart failure, hepatosplenomegaly, and the haematological features of hypersplenism is presented. The haematological abnormalities were corrected after tricuspid valve replacement but recurred with the reemergence of clinical features of right heart failure.
\end{abstract}

Ebstein's anomaly often results in right heart failure with an increase in systemic venous pressures. The latter, when transmitted as raised portal venous pressures, can cause splenomegaly and the haematological features of hypersplenism. The occurrence of reversible hypersplenism associated with changes in right sided pressures in Ebstein's anomaly has not been described before.

\section{Case report}

Ebstein's anomaly was diagnosed in a child with cyanosis on exertion, characteristic physical findings, and radiological evidence of cardiomegaly. He remained well, however, without treatment, until the age of 35 when he presented with dyspnoea and epistaxis. On examination he had cyanosis at rest, features of right heart failure with tricuspid regurgitation, hepatosplenomegaly, and widespread purpura. Investigations performed at that time showed a haemoglobin concentration of $188 \mathrm{~g} / 1$ (normal range 135-165), white cell count of $3.0 \times 10^{9} / 1$ (normal range 4.0-11.0 $\times$ $\left.10^{9} / 1\right)$, and a platelet count of $75 \times 10^{9} / 1$ (normal range 150-450 $\times 10^{9} / 1$ ). Cardiac catheterisation showed raised right sided pressures and tricuspid regurgitation (table) and normal left sided pressures. At operation, undertaken on the basis of symptoms and evidence of heart failure, the tricuspid valve was shown to be incompetent with an aneurysmally dilated right atrium, small right ventricle, and a patent foramen ovale. The
Department of Queen Elizabeth Hospital, Birmingham M R Bennett

MF Shiu

Correspondence to Dr M R Bennett,

Department of Cardiology, University of Wales Colleg of Medicine, Heath Park, Cardiff CF4 4XN. tricuspid valve insertion was typical of Ebstein's anomaly. Initial surgical intervention was plication of the right atrium, which made the tricuspid valve competent, together with closure of the foramen ovale. However, there was little improvement in symptoms after this operation. Right heart failure became worse over the next two years and he required further admissions. Investigations at this time showed a haemoglobin concentration of $175 \mathrm{~g} / \mathrm{l}$, a fall in his white cell count to $2.2 \times 10^{9} / 1$, and a platelet count of $70 \times 10^{9} / 1$. Cardiac catheterisation showed a further increase in his right sided pressures (table) and another operation was considered.

The tricuspid valve was replaced with a Starr-Edwards prosthesis two years after valvoplasty and his clinical signs of right heart failure resolved with a considerable improvement in symptoms. This was associated with a dramatic reduction in his hepatosplenomegaly as assessed clinically and on abdominal radiography and a sharp rise in his neutrophil and platelet counts, which restored them to normal (figure). Between 1978 and 1989 signs of right heart failure gradually reemerged with progressive hepatosplenomegaly and concomitant falls in his neutrophil and platelet counts (figure). Cardiac catheterisation showed a further increase in right sided pressures (table).

At each admission the patient was investigated for causes of his pancytopenia. Bone marrow samples showed a consistently hypercellular marrow, with increases in all cell

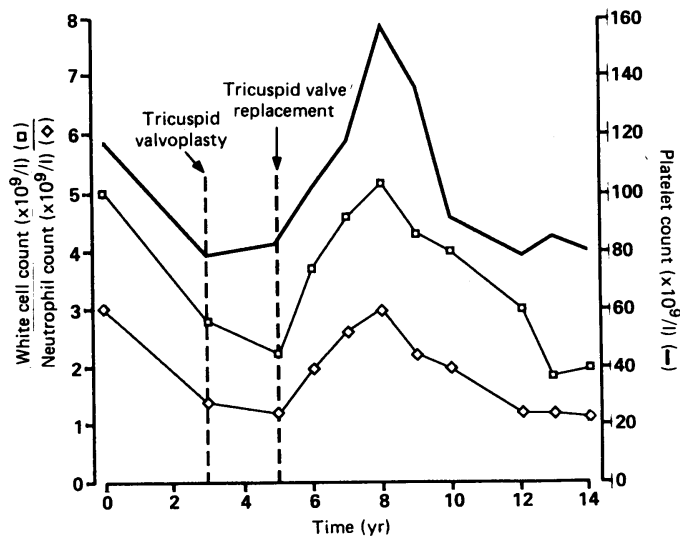

White cell, neutrophil, and platelet counts during each operation and at follow up. (Means of three observations.)
Pressure recordings (systolic/diastolic ( $\mathrm{mm} \mathrm{Hg}$ )) at cardiac cathe
operation and 16 years after replacement of the tricuspid valve

\begin{tabular}{lllll}
\hline Chamber & $\begin{array}{l}\text { Before } \\
\text { valvoplasty }\end{array}$ & $\begin{array}{l}\text { Before triscuspid } \\
\text { valve replacement }\end{array}$ & $\begin{array}{l}\text { 16 years after } \\
\text { tricuspid valve replacement }\end{array}$ \\
\hline $\begin{array}{l}\text { Right atrium } \\
\text { Right ventricle }\end{array}$ & $11 / 1 \quad($ mean $=6)$ & $30 / 15 \quad($ mean $=24)$ & $33 / 20 \quad$ (mean $=27)$ \\
\hline
\end{tabular}


lines, but no evidence of megaloblastosis, dysplasia, or infiltration. Intravascular haemolysis was excluded by a normal peripheral blood film, serum haptoglobin, and urinary haemosiderin. Coombs test and the Ham acid lysis test were negative and serum vitamin $B_{12}$ and folate concentrations were normal. AntiDNA antibodies and the rheumatoid arthritis latex test were negative. Infective endocarditis was excluded by repeated negative blood cultures. The pancytopenia was therefore attributed to hypersplenism. An ultrasound scan of the abdomen confirmed hepatic venous congestion and hepatosplenomegaly, and the presence of splenic varices implied portal hypertension, though the portal vein was patent and of normal size.

\section{Discussion}

Hypersplenism is defined as a depression of one or more of the cell counts in the circulating blood that can be wholly attributed to splenic enlargement and is associated with a cellular bone marrow. ${ }^{1}$ Other causes of pancytopenia: hypersplenism, marrow aplasia/ dysplasia, marrow infiltration, megaloblastosis, systemic lupus erythematosis, and paroxysmal nocturnal haemoglobinuria were excluded as indicated above. The patient's initial polycythaemia is usual in cases of Ebstein's anomaly with right to left shunt, ${ }^{2}$ and was corrected by closure of the shunt.

Our patient with Ebstein's anomaly had had chronic right heart failure with raised systemic venous pressures for many years. Chronic right heart failure with hepatic venous congestion is associated with splenomegaly in $12-25 \%$ of patients ${ }^{3-5}$; the mechanism is believed to be portal venous hypertension secondary to raised hepatic ven- ous pressures. Moderate to severe symptoms in Ebstein's anomaly or the presence of heart failure are regarded as indications for tricuspid valve plication or replacement. ${ }^{6} \mathrm{Re}-$ placement has been shown to reduce right atrial pressures, ${ }^{6}$ and should therefore reduce both systemic and portal venous pressures. Reduction in portal venous pressures, for example after distal spleno-renal shunting procedures, reversed the neutropenia and thrombocytopenia of hypersplenism and this was associated with a reduction in splenic size. $^{78}$

Hypersplenism in our patient seems to be the result of raised systemic (and thus portal) venous pressures, and treatment of the cardiac lesion with reduction in these pressures improved the secondary haematological characteristics. Such an association between Ebstein's anomaly and hypersplenism has not been described before; perhaps because detailed longitudinal studies over many years are often not possible. Our patient is also unusual because he has survived 17 years after the onset of heart failure-a poor prognostic sign in patients with Ebstein's anomaly.

1 Richmond J. Hypersplenism. Br J Hosp Med 1980;24: 405-11.

2 Danielson GK, Foster V. Surgical repair of Ebstein's anomaly. Ann Surg 1982;196:499-503.

3 White TJ, Leevy CM, Bruscaz AM, et al. The liver in congestive heart failure. Am Heart J 1955;49:250-7.

4 Garvin CF. Cardiac cirrhosis. Am J Med Sci 1943;205 515-8.

5 Richman SM, Dolman AJ, Grob D. Alterations in indices of liver function in congestive heart failure with particula reference to serum enzymes. Am J Med 1961;30:211-25.

6 Abe T, Kometsu S. Valve replacement for Ebstein' anomaly of the tricuspid valve. Chest 1983;84:414-7.

7 Hudson DG, Deppa R, Levi J, et al. The effect of distal splenorenal shunt on hypersplenism. Ann Surg 1977;185: 605-10.

8 Ferra J, Ellison C, Martin EW, Cooperman M. Correction of hypersplenism following distal splenorenal shunt. Surgery 1979;86:570-3. 